\title{
Where are we going with preimplantation genetic diagnosis?
}

\section{Timothy Krahn}

I n Canada, preimplantation genetic diagnosis is governed by the Assisted Human Reproduction Act, ${ }^{1}$ which received royal assent on Mar. 29, 2004. Regulations for preimplantation genetic diagnosis in accordance with the act are currently being developed after a series of ongoing public consultations. To regulate uncertain and controversial public policy issues, such as assisted human reproduction, the Canadian government has an established history of taking its bearings from the best practises, policy precedents and relevant regulatory structures in the United Kingdom. ${ }^{2,3}$ In light of this history, it is fitting for us to pay attention to recent developments in the United Kingdom.

On May Io, 2006, the United Kingdom's Human Fertilisation and Embryology Authority published its decision to license preimplantation genetic diagnosis for hereditary breast and ovarian cancer (BRCAI and BRCA2 mutations) and hereditary non-polyposis colorectal cancer. ${ }^{4}$ These conditions are distinct from those previously licensed to be tested for in the United Kingdom because of a combination of 3 factors: they have a later age of onset, they are lower penetrance conditions (up to $80 \%,{ }^{5}$ compared to the previous threshold of more than $90 \%$ penetrance ${ }^{6}$ ) and they are potentially treatable. Before this decision, the Human Fertilisation and Embryology Authority had licensed preimplantation genetic diagnosis for conditions for which I, or at most 2, of these 3 factors applied. By permitting preimplantation genetic diagnosis for these hereditary adultonset cancers, the Human Fertilisation and Embryology Authority has effectively downgraded its criteria for "significant risk of being affected by a serious inherited genetic condition." The purpose of this commentary is to consider the moral dangers associated with this ruling in terms of its potential resonating effects on the normative fabric of our culture.

In much of the Western world, where parents are having fewer children, where some parents are having children after the experience of infertility and where prenatal diagnosis and preimplantation genetic diagnosis are promoted as part of good prenatal care, we are developing a culture that is overly directed by the interests of some well-intentioned, but perhaps misguided, prospective parents (and possibly more exacting clinicians) committed to having healthy children. The underlying beliefs are as follows: Because parents are having fewer children, it is both common sense and in the best interests of the children that they be given the "best" genetic prospects. Moreover, from a societal perspective, if the health care system and social services are unable to assume the full burden of treating serious genetic conditions, then it seems only just that the present generation use all reasonable means of preventing these conditions. Indeed, such reasoning probably explains a certain societal sympathy for people who want to test their embryos for potentially heritable conditions. The moral danger does not lie with the people who seek the testing; rather, the danger lies in how this testing could promote further stigmatization of and discrimination against people with "genetic impairments" ${ }^{8-10}$ or their parents. ${ }^{11}$ Indeed, testing could entrench a culture of prevention and perfectionism and promote a culture of intolerance.

As the number of genetic tests for conditions with lower penetrance increases and these tests become more widely available, parents may have increased expectations of having "normal and healthy" (i.e., unaffected) offspring. This desire could subtly shift parents' attitudes toward their embryos (and eventually their children) if their embryos are treated more and more like consumer products subject to a process of quality control.

One serious limitation of preimplantation genetic diagnosis is that it focuses narrowly on evidence of genetic anomalies (deviations from the norm that may not even be expressed). The risk is that evidence of genetic conditions or predispositions may become the overriding or sole factor in the process of embryo selection and that decision-makers may value only that which they can test for as dictated by the current state of available technology. In the end, this practice of selecting against certain genetic characteristics could further upgrade the standards of "normality" and compress the spectrum of "healthy," with the result that many human imperfections might become "less tolerated and less likely to be accepted as normal human variation."12

Widespread efforts at prevention and perfectionism could seed a culture of intolerance. Of particular concern is the risk of exacerbating social problems for people with conditions for which genetic testing is available. Increases could be seen in resources that are directed at finding ways to diagnose and screen embryos for genetic conditions by preimplantation genetic diagnosis. Correspondingly, reductions could be seen in resources to provide health care support and treatment for people living with these same conditions. ${ }^{13,14}$ Even the practice of labelling and singling out certain genetic conditions as "serious" and therefore test-worthy holds the danger of giving medical validation to some of our deepest fears and prejudices about what it is to live with, or to support people with, cognitive or physical impairments. Some have even suggested that we cannot brake on this slippery slope by applying more stringent criteria of what counts as a significant risk for a "serious" genetic condition (i.e., a condition valued negatively by the medical profession and society that is deemed worthy of screening against for reasons that extend beyond parental preference). From this perspective, to better avoid the prejudice and stigmatization of "impairment" associated with screening for serious conditions, 
it may be preferable to have parental choice alone as the sole justification required for screening. Otherwise, by marking off a special class of genetic conditions as serious we risk making it seem like the decision against having a child with a "serious" condition is prima facie more legitimate than the decision to resist this entrenched prejudice in our society. ${ }^{14}$

The recent decision by the Human Fertilisation and Embryology Authority has put us on an undetermined path where we could lose sight of, or even come to have contempt for, people who are "genetically disadvantaged." Given what we as Canadians can learn from British policy and practice in these matters, we need to ask ourselves: Where are we going with these new genetic technologies? Should we be so sanguine about having preimplantation genetic diagnosis take us there? What are we sacrificing to gain control over genetic conditions? Doesn't authentic control include knowing not only where to start, but also where to stop?

As archeologists know, future generations can learn about the values and norms of previous generations as much by examining their garbage as by examining their achievements. Given this analogy, what might our descendants learn about our culture by observing not only which policy choices are taken up, but also by which ones are discarded? Abby Lippman reminds us that "There are choices to be made and the choices will reflect our values and ideology. How we choose our culture (by the routes we take) is no less problematic than how we choose our children, and consequences from both will be among our legacies." ${ }^{15}$ We would do well to heed her admonition.

This article has been peer reviewed.

Timothy Krahn is with Novel Tech Ethics, Dalhousie University, Halifax, NS.

Competing interests: None declared.

Acknowledgements: I would like to thank Françoise Baylis, Olga Kits and Lynette Reid for their comments on earlier drafts of this commentary.

This work was supported by a grant from the Canadian Institutes of Health Research (CIHR).

\section{REFERENCES}

I. Assisted Human Reproduction Act, SC 2004, c 2, Sio(2), 40(I).

2. Jones M, Salter B, Pigeon N. RES-000-22-0987 - Policy transfer in risk governance: lessons from the UK biotechnology framework. London (UK): Economic and Social Research Council; 2006. Available: www.esrcsocietytoday.ac.uk/ESRCInfoCentre /Plain_English_Summaries/work_organisation/innovation_change/index27.aspx? ComponentId= $15624 \&$ SourcePageId $=1707$ (accessed 2007 Mar 30).

3. Jones $M$. What can one nation learn from another? Exploring policy choice in the new Canadian framework for assisted human reproduction. London (UK): BioNews.org.uk; 2005 Oct 3. Available: www.bionews.org.uk/commentary.lasso? storyid $=2765$ (accessed 2007 Mar I6).

4. Human Fertilisation and Embryology Authority. Authority decision on the use of PGD for lower penetrance, later onset inherited conditions. London (UK):The Authority; 2006. Available: www.hfea.gov.uk/docs/The_Authority_decision Choices_and_boundaries.pdf (accessed 2007 April 2).

5. Human Fertilisation and Embryology Authority. Choices \& boundaries report 2006 a summary of responses to the HFEA public discussion. London (UK): The Authority; 2006. Available: www.hfea.gov.uk/cps/rde/xbcr/SID-3F 57 D79B-8FC 36 EC9 /hfea/Choices_and_boundaries_Report_2006.pdf (accessed 2007 Mar 9).

6. Human Fertilisation and Embryology Authority. Choices and boundaries: Should people be able to select embryos free from an inherited susceptibility to cancer? London (UK): The Authority; 2005. Available: www.hfea.gov.uk/cps/rde/xbcr /SID-3F57D79B-5AoCCi7F/hfea/Choices_and_Boundaries.pdf (accessed 2007 Mar 30).

7. Human Fertilisation and Embryology Authority. Code of practice. 6th ed. London (UK): The Authority; 2003. Available: www.hfea.gov.uk/cps/rde/xbcr ISID-3F57D79B-FAAAF985/hfea/Code_of_Practice_Sixth_Edition_-_final.pdf (accessed 2007 Mar 9).

8. Harris M, Winship I, Spriggs M. Controversies and ethical issues in cancer-genetics clinics. Lancet Oncol 2005;6:30I-Io.

9. Asch A. Disability equality and prenatal testing: Contradictory or compatible? Fla State Univ Law Rev 2003;30:315-42.

Io. Matloff ET, Shappell H, Brierley K, et al. What would you do? Specialists' perspectives on cancer genetic testing, prophylactic surgery and insurance discrimination. IClin Oncol 2000;18:2484-92.

II. Marteau TM, Drake H. Attributions for disability: the influence of genetic screening. Soc Sci Med I995;40:1127-32.

I2. Beeson D. Social and ethical challenges of prenatal diagnosis. Med Ethics (Burlington, Mass) 2000 Winter;I-2,8. Available: www.lahey.org/Pdf/Ethics /Winter_2000.pdf (accessed 2007 Mar 30).

I3. Holtzman NA, Shapiro D. Genetic testing and public policy. BMJI998;316:852-6.

I4. Wasserman D, Asch A. American Medical Association. The uncertain rationale for prenatal disability screening. Virtual Mentor. 2006; 8: 53-56. Available: www.ama-assn org/ama/pub/category/print/15809.html (accessed 2007 Mar 9).

I5. Lippman A. Prenatal genetic testing and screening: constructing needs and reinforcing inequities. Am J Law Med I991;17:15-50.

Correspondence to: Timothy Krahn, Novel Tech Ethics, Intellectual Commons, Dalhousie University, 1234 LeMarchant St., Halifax NS B3H 3P7; fax 902 494-2924; tim.krahn@dal.ca

\begin{tabular}{|l|l|} 
Reprints & $\begin{array}{l}\text { Bulk reprints of CMAJ articles are available in minimum quantities of } 50 \\
\text { For information or orders: } \\
\text { Reprint Coordinator } \\
\text { tel } 800663-7336 \times 2110, \text { fax } 613 \text { 565-7704 } \\
\text { janis.murrey @ cma.ca }\end{array}$ \\
\hline
\end{tabular}

